\title{
Thomas McKeown, Meet Fidel Castro: Physicians, Population Health and the Cuban Paradox
}

\section{Thomas McKeown, rencontre avec Fidel Castro : Médecins, santé de la population et paradoxe cubain}

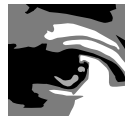 \\ by ROBERT G. EVANS \\ Professor of Economics, University of British Columbia \\ Vancouver, BC
}

\begin{abstract}
About 40 years ago, Thomas McKeown demonstrated that the historic decline in the great killer diseases owed little or nothing to progress in medicine. A generation of research on population health followed, highlighting the large social gradients in health within populations. These vary greatly across societies, but appear largely unrelated to medical care. Medicine was acknowledged as "powerful, but within limits"; the major determinants of health lie elsewhere.

We may have missed something. Cuba has achieved "first world" population health status despite a minimal economic base. Far from marginalizing medicine, Cuba has by far the world's largest physician workforce. But doctors' roles are significantly expanded. The system seems to work.
\end{abstract}




\section{Résumé}

Il y a environ 40 ans, Thomas McKeown démontrait que le déclin historique des principales maladies mortelles était peu ou pas du tout attribuable aux progrès de la médecine. Depuis, les nombreuses recherches sur la santé des populations ont mis en relief l'ampleur des gradients sociaux de la santé au sein des populations. Ces gradients varient énormément d'une société à l'autre, mais semblent peu liés aux services médicaux. Il a été reconnu que la médecine était « puissante, bien que limitée »; les principaux déterminants de la santé se trouvant ailleurs.

Il est possible que nous ayons passé outre quelque chose. Cuba est parvenue à un statut de santé comparable à celui des pays industrialisés, et ce, en dépit d'un tissu économique limité. Loin de marginaliser la médecine, Cuba est dotée du plus important effectif de médecins au monde. Mais leur rôle y est largement étendu. Le système semble bien fonctionner.

вout 40 years ago, Thomas McKeown Fired a Shot across the bow
of medicine whose echoes still reverberate faintly. Studying mortality records
for England that go back to the first half of the 19th century, he demonstrated that the very large declines in mortality from a number of major infectious diseases pre-dated not only the development of effective medical therapies but also scientific understanding of the disease processes themselves (McKeown 1979). The major killers of the 19th century are still around, but their impact on the health of the English population, or any other high-income population, has almost disappeared - for reasons quite independent of medical progress. As a "diagnosis of exclusion," McKeown "emphasized instead the importance of economic growth, rising living standards, and improved nutrition as the primary sources of most historical improvements in the health of nations" (Szreter 2002).

Human society has been transformed over the last century and a half by the decline in mortality at all ages and the increase in life expectancies. Over the same period there have been enormous advances in biomedical science, and in the last half century these have translated into huge increases in the resources devoted to the provision of medical care. (Between 1960 and 2005, the share of greatly increased national incomes spent on healthcare in OECD countries more than doubled; in the United States it tripled.) It is intuitively plausible to assume that these trends are causally linked - post hoc ergo propter hoc.

The general public are happy to give modern medical care credit for these great benefits, and the providers of care have been willing to accept. McKeown's demonstration that correlation is not the same as causation, at least with respect to infectious 
disease, was understandably unpopular and controversial. He could not be directly refuted - the data and the timing were what they were - but clinicians largely ignored his observations. Anyway, that was then; this is now.

Furthermore, McKeown somewhat overplayed his hand. His leading example, tuberculosis, does in fact show a marked downturn in mortality rates in the late 1940s, when effective medical therapy was developed. In the long historical sweep, the overall decline is so large that it is easy to miss this kink, but in relative terms - and to the patients and doctors of the late 1940s - the effect was very significant. They might understandably reject the claim that "medicine doesn't matter" while missing the crucial point that on the larger historical scale, other and more powerful factors had been at work.

\section{But Public Health Matters -- or Did?}

Perhaps more seriously, McKeown took too restrictive a view of those other factors. Because TB is not a water-borne bacillus, he argued that the decline in TB mortality could not be a result of cleaner water and better sewage disposal. Public health measures deserved no more credit than medicine. This interpretation was effectively challenged by Szreter (1988), who noted that TB was an "opportunistic" infection, taking advantage of the presence of other infections that were water-borne. Gastro-intestinal diseases, in particular, tend to reduce the nutritional uptake from food consumption. But sanitary measures reducing the prevalence of gastro-intestinal disease could then increase the nutritional value of diets, and more generally improve "host resistance." No matter how wealthy you are, drinking sewage is a seriously bad idea.

McKeown's medical scepticism continues to find support, however, in aggregate data on population health. When compared across high-income countries, measures such as life expectancy, age-adjusted mortality or potential years of life lost do not show a correlation with expenditures on healthcare or the available supply of doctors or other personnel, or hospital capacity. Nor, however, do they show any correlation with average per capita income levels. In low-and middle-income countries there is quite a strong correlation with both income and health spending, making it impossible to infer anything about which, if either, is the more important factor.

Yet there is within high-income countries a more or less pronounced gradient in health that is closely correlated with income, education and other measures of social status. There is thus a paradox: within countries, income is correlated with health, but among (high-income) countries, it is not. This observation underlies a generation of research on the social determinants of health, with particular interest in how social position influences health status, and thus in the relative equality or inequality of social positions in different societies. 


\section{Population Health and Medicine: Two Solitudes?}

Medicine is not among the potential explanations. Virtually all high-income countries have more or less universal access to modern healthcare systems, leading researchers to discount the significance of medical care as an explanation of the social gradient. Where there are identifiable populations with significantly restricted access to healthcare, one can in fact observe corresponding health consequences - as among the uninsured population in the United States. Medicine does matter. But the more intellectually challenging question has been the sources of the social gradient in the general populations of high-income countries.

The marginalization of the medical profession that was explicit in McKeown's findings has thus continued through the subsequent generation of research on the determinants of population health. No one would now deny the powerful contribution of modern medicine to improvements in longevity, function and quality of life of individuals. But it is, I think, fair to say that the general attitude of students of population health is that medical care is "powerful within limits" and cannot explain the major gradients in health within populations any more than it can explain the historical changes studied by McKeown.

This view has only been strengthened by a generation of research on variations in patterns of clinical care. The most intensive investigations, in the United States, find that regions with greater volumes and higher costs of care actually have no greater patient satisfaction, slightly worse mortality outcomes and lower quality of care (see Evans 2007 for references). Where there are more doctors, and greater hospital or equivalent capacity, costs are much higher but outcomes are worse, not better.

It is therefore not surprising that study of the social determinants of health has been viewed by most physicians with at best, indifference and at worst, outright hostility. It is seen as a potential threat to their status - and their incomes. (Ironically, most of the leading students of the social determinants of health, from Rudolf Virchow to Sir Michael Marmot and Fraser Mustard - and including that medical iconoclast, Thomas McKeown - have been physicians.)

But students of population health (present company included) may have missed something.

\section{The Black Swan}

The exception, it is often said, proves the rule. ("Proves" here has its original meaning of testing, not confirming.) One black swan suffices (subject to a bit of scrubbing) conclusively to refute the proposition "All swans are white." The Cuban experience, over the last 50 years, may be just such a black swan. Spiegel and Yassi (2004:204) refer to it as "the Cuban health paradox": 
Thomas McKeown, Meet Fidel Castro: Physicians, Population Health and the Cuban Paradox

It is widely recognized that Cuba, despite poor economic performance, has achieved and sustained health indices comparable to those in developed countries....

The remarkable Cuban achievement with respect to population health emerges clearly from the World Health Report (WHR) (WHO 2006). Figures $1 \mathrm{a}$ and $1 \mathrm{~b}$ combine data from the Statistical Annex to show the relationship between per capita GDP and two different measures of population health - life expectancy at birth and expected mortality per thousand population under five years of age. ${ }^{1}$ Both figures show a similar pattern, with a strong overall relation between income levels and health status but with very important qualifications. ${ }^{2}$

FIGURE 1A. Life expectancy at birth plotted against GDP per capita, 139 countries

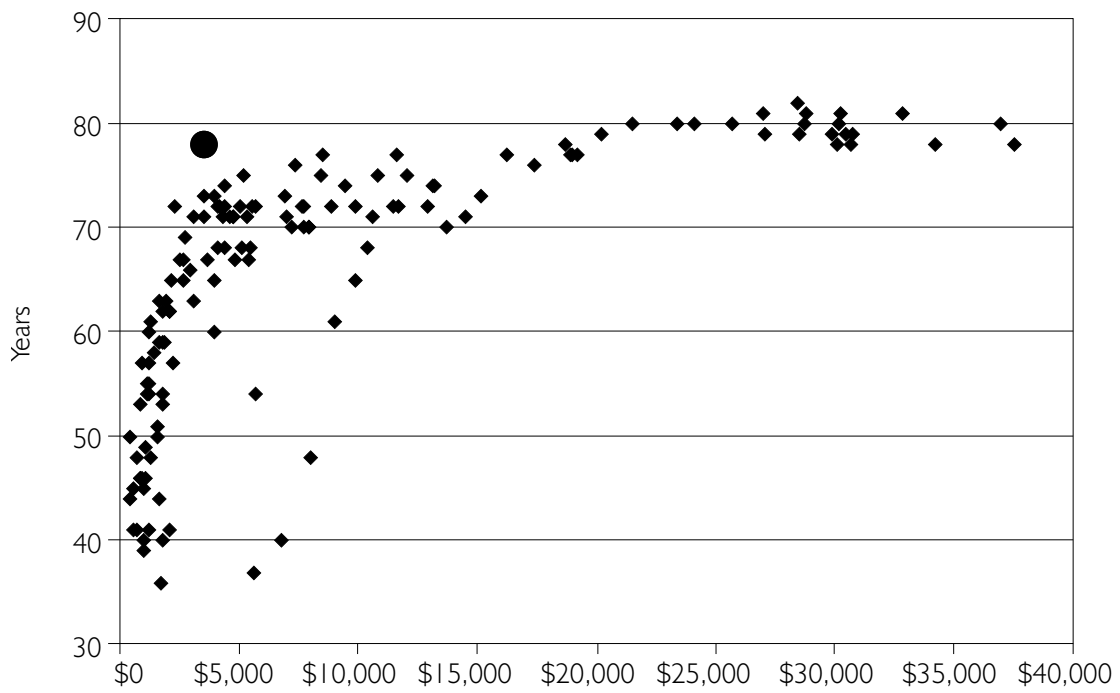

Source: WHO 2006, Statistical Annex, Tables I and 3.

In high-income countries there is no relationship between per capita GDP and either of these measures of health status. For mortality under five years of age, the relationship disappears above a per capita GDP of $\$ 15,000$; for life expectancy, there is some suggestion of a relationship up to $\$ 20,000$ per capita. But the relationship is unclear among countries at the very lowest incomes. A fitted trend line would indicate a very powerful relationship, but comparison of individual country observations shows very large differences in health measures for countries with the same reported levels of income. Inter-country differences in factors other than income are obviously exerting a very powerful effect on health - which is not the case for higher-income countries. 
FIGURE 1B. Mortality before age 5 plotted against GDP per capita, 139 countries

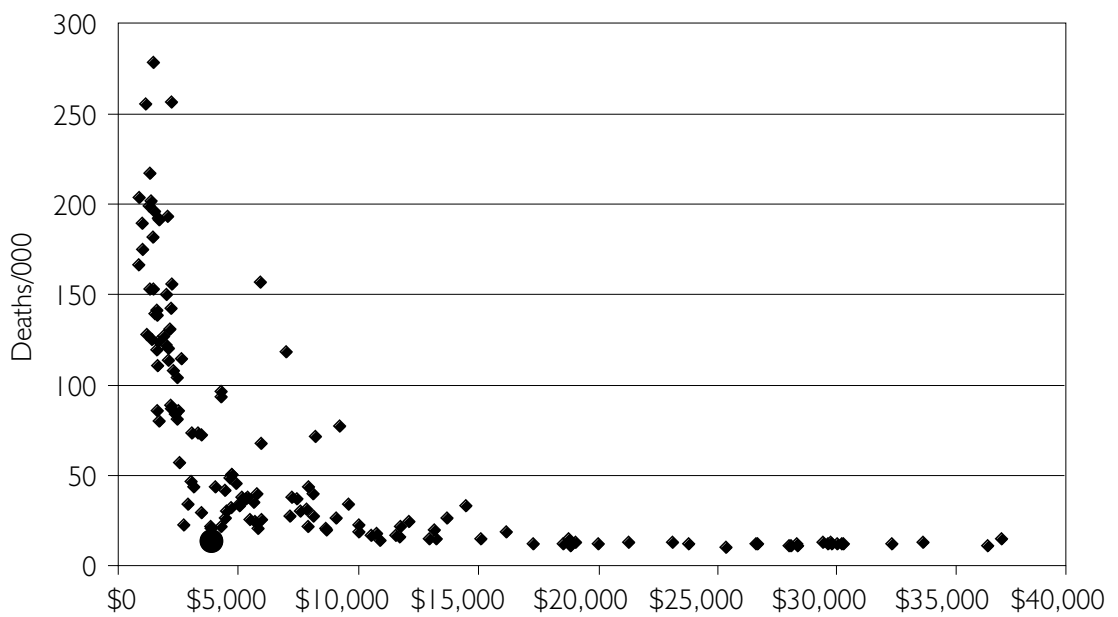

Source: WHO 2006, Statistical Annex, Tables I and 3.

And then there is Cuba.

High up on the far left for life expectancy, and low down on the left for under-five mortality (expanded circles), Cuba's health measures are comfortably within the band of the highest-income countries while its per capita income, at $\$ 3,438$, places it 86 th among the 139 countries plotted - roughly in the middle of the third quartile. The health of Cuba's population matches or exceeds, on average, that of the United States. Among countries with similar income levels, the best achieve under-five mortality rates twice that of Cuba, and the rest are three, four or five times as high. The best life expectancies are five years shorter; others are 10 or more years shorter. The differences are extraordinary.

The world data span the full range of cultures and environments. Figures $2 \mathrm{a}$ and $2 \mathrm{~b}$ restrict attention only to the Americas. But they tell the same story, permitting the graph to be spread out more widely. The wealth and good health of Canada and the United States stand out on one side of the figure; the poverty and ill health of Haiti on the other. But in number two position on life expectancy, behind Canada and in a tie with the United States, is Cuba. Chile and Costa Rica are right behind, but with much higher income levels than Cuba. And on child mortality, Cuba edges out the United States and Chile to lie right behind Canada. The margin over other countries runs from large to very large.

So what is happening in Cuba?"There has been remarkably little scholarship evaluating how this has been accomplished..." (Spiegel and Yassi 2004). This column will not fill that gap. But there is one other remarkable feature of Cuban healthcare that does jump out of the WHR data. 


\section{Doctors and Good Health; No Clear Relationship, But ...}

Cuba's doctor-to-population ratio -5.91 per thousand - is by a substantial margin the highest in the world. ${ }^{3}$ Figures $3 \mathrm{a}$ and $3 \mathrm{~b}$ show the reported physician-to-population ratios, for all countries and for those only of the Western hemisphere, plotted against per capita GDP. For countries with incomes under about $\$ 10,000$ there appears (in Figure 3a) to be a relationship between income levels and physician availability, branching out from a large concentration of countries that have neither money nor doctors. Above $\$ 10,000$, however, there is no clear relationship - the observations simply spray across the page.

There are many countries with a much greater physician supply than the United States or Canada, even with incomes well below $\$ 10,000$. But Cuba stands out at the upper left, far above the next highest, Belarus at 4.55, Belgium at 4.49 and Estonia at 4.48. There are a lot of doctors in Cuba.

FIGURE 2A. Life expectancy at birth plotted against GDP per capita, the Americas

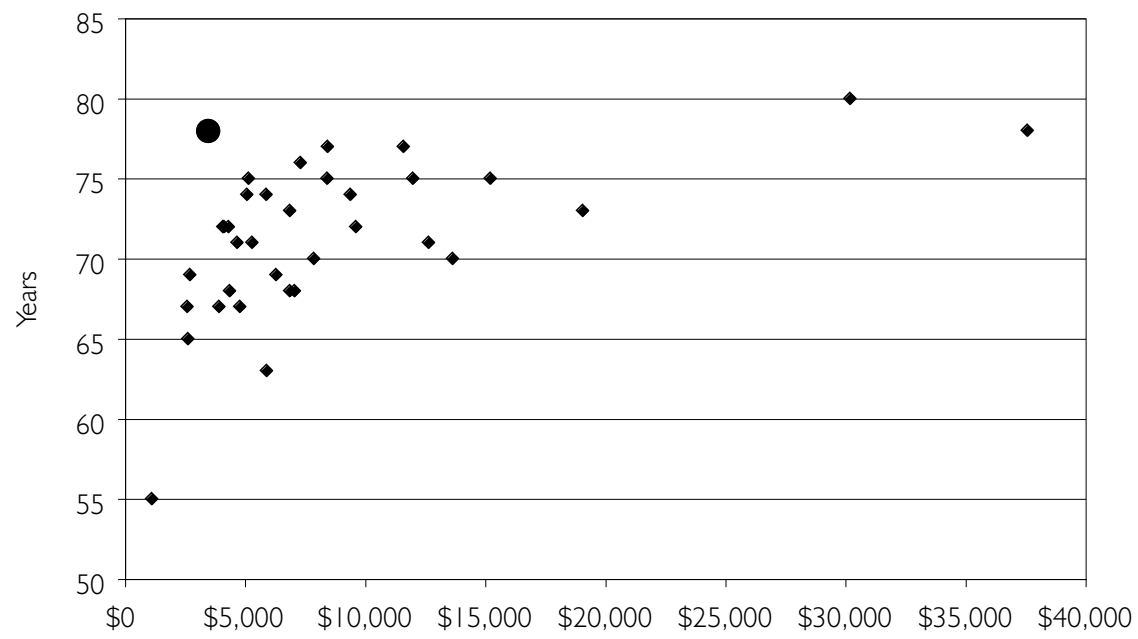

Source: WHO 2006, Statistical Annex, Tables I and 3.

Belgium and Belarus, however, make a convenient comparison, underlining the significance for health of the broader social context. Belgium's life expectancy, at 78, matches that of Cuba or the United States, and the under-five mortality of 5 is better than either Cuba (7) or the United States (8). Life expectancy in Belarus is a full 10 years shorter, and child mortality is exactly double that of Belgium. Estonia is between the two, at 72 and 8.

Canada, on the other hand, matches or exceeds the health outcomes of the most heavily doctored European countries - Italy and Greece, as well as Belgium - with half as many physicians. And Japan has fewer still (1.98 per thousand) and the best outcomes in the WHR. 
FIGURE 2B. Mortality before age 5 plotted against GDP per capita, the Americas

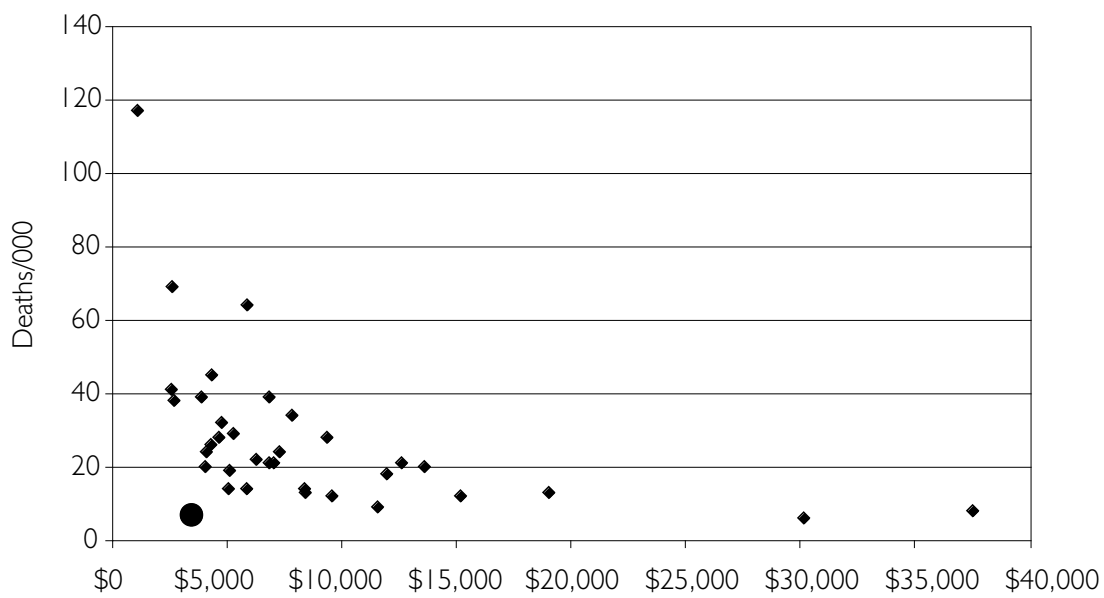

Source: WHO 2006, Statistical Annex, Tables I and 3.

FIGURE 3A. Physicians per I,000 population plotted against GDP per capita, I 39 countries

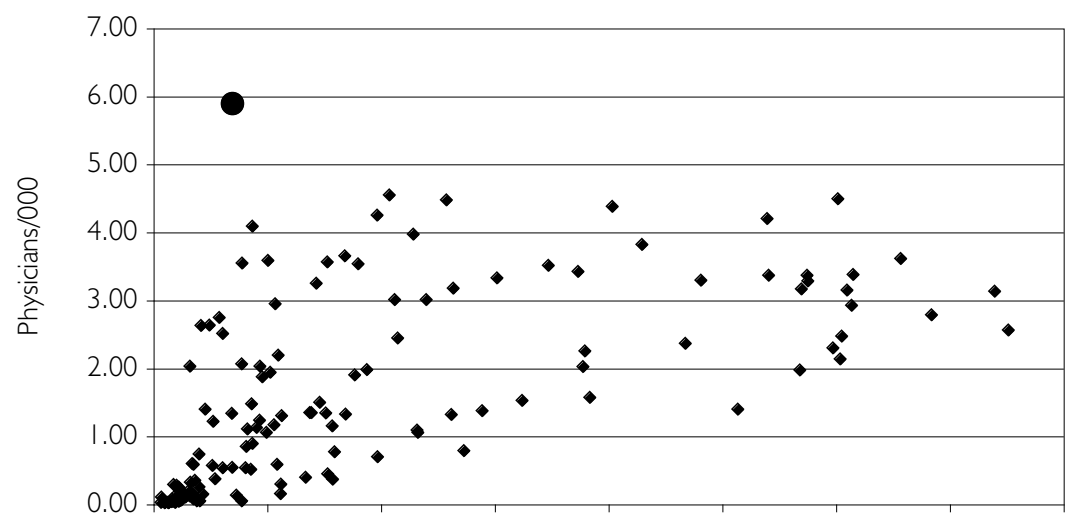

$\$ 0 \quad \$ 5,000 \quad \$ 10,000 \quad \$ 15,000 \quad \$ 20,000 \quad \$ 25,000 \quad \$ 30,000 \quad \$ 35,000 \quad \$ 40,000$

Source: WHO 2006, Statistical Annex, Tables 3 and 4.

A focus on the Americas alone, as in Figure 3b, may avoid some of the more extreme variations in culture and geography. But the tight clustering of American countries results from the presence of extreme outliers with respect to income (Canada and the United States) and physician supply (Cuba). There appears to be a slight positive relationship within the main cluster, but any statistical fit would be extremely sensitive to the inclusion or exclusion of outliers. There are, however, a handful of other countries besides Cuba that have relatively high physician-to-population ratios, without achieving comparable health outcomes (Table 1). 
Thomas McKeown, Meet Fidel Castro: Physicians, Population Health and the Cuban Paradox

The other American states with particularly high physician availability show health outcomes markedly inferior to those in Cuba. The wealthy North American pair achieves results comparable to Cuba with many fewer physicians, but Mexico, with a physician supply not far below that in Canada, has significantly poorer outcomes. On the other hand, Chile, with about half as many physicians as Mexico or Canada, has health outcome measures comparable to the United States - and less than one-third the per capita income. That still amounts, however, to over three times the per capita income of Cuba.

FIGURE 3B. Physicians per 1,000 population plotted against GDP per capita, the Americas

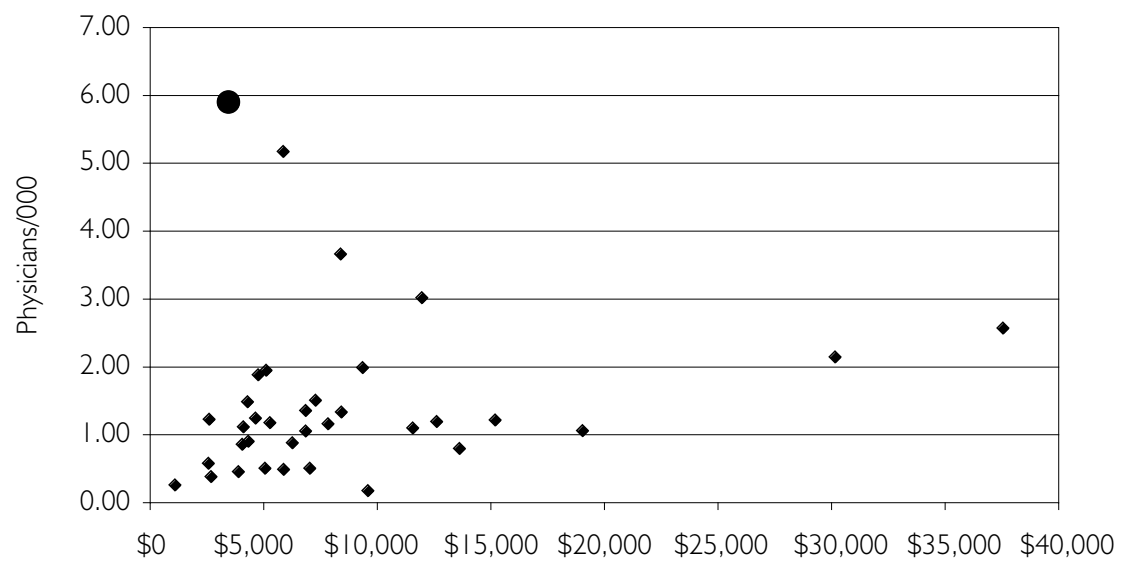

Source: WHO 2006, Statistical Annex, Tables 3 and 4.

TABLE 1. Physician supply, life expectancy, mortality under age five and GDP per capita, the Americas

\begin{tabular}{|l|l|l|l|l|}
\hline Country & $\begin{array}{l}\text { Physicians per } \\
\text { I,000 population }\end{array}$ & $\begin{array}{l}\text { Life expectancy } \\
\text { at birth }\end{array}$ & $\begin{array}{l}\text { Mortality } \\
\text { under age 5 }\end{array}$ & GDP per capita \\
\hline Cuba & 5.91 & 78 & 7 & $\$ 3,438$ \\
\hline St. Lucia & 5.17 & 74 & 14 & $\$ 5,880$ \\
\hline Uruguay & 3.65 & 75 & 14 & $\$ 8,408$ \\
\hline Argentina & 3.01 & 75 & 18 & $\$ 11,989$ \\
\hline United States & 2.54 & 78 & 8 & $\$ 37,572$ \\
\hline Canada & 2.14 & 80 & 6 & $\$ 30,192$ \\
\hline Mexico & 1.98 & 74 & 28 & $\$ 9,387$ \\
\hline Chile & 1.09 & 77 & 9 & $\$ 11,590$ \\
\hline
\end{tabular}

Source: WHO 2006, Statistical Annex, Tables I and 4. 


\section{Wealth and Health: Neither Necessary Nor Sufficient?}

I promised above not to offer an explanation for the "Cuban Paradox," but the combination of "first world" health statistics from a "third world" economic base, like the black swan, refutes "the conventional assumption that generating wealth is a fundamental precondition for improving health" (Spiegel and Yassi 2004). There is certainly a strong cross-national association between health and wealth over part of the income range, although the association disappears above relatively modest levels of average income. But there are alternatives; increased wealth is not a necessary condition for improved health, even among middle- and low middle-income countries.

Nor is it a sufficient condition. The strong relationship shown in Figures $1 \mathrm{a}$ and $1 \mathrm{~b}$ covers a considerable degree of diversity in the middle-income ranges. Costa Rica, with a per capita GDP of $\$ 8,438$, has an average life expectancy of 77 years - just below the United States and Cuba. South Africa, with an income of $\$ 7,964$, has a life expectancy of 48 years. Kazakhstan $(\$ 9,000)$ has a life expectancy of 61 , while Thailand $(\$ 7,879)$ and Brazil $(\$ 7,855)$ have life expectancies of 70 .

If McKeown was right - that increasing wealth is the highway to better health - a number of countries seem to have misplaced the map.

\section{Conscious Political Will - and People Trained to Carry It Out}

Szreter's response to McKeown goes well beyond the epidemiology of tuberculosis. The much broader issue is the role of explicitly targeted social policy, of "an accompanying redistributive social philosophy and practical politics" (Szreter 2002) in the 19th century public health movement, simultaneously with the trends observed by McKeown. The revolution in population health over the last two centuries was not simply a side effect of a rising GDP, it was achieved through the deliberate intentions and actions of people with a social agenda. Any idea that "go for growth, and all else will be added unto you" would be a dangerous distortion of the historical reality.

The Cuban experience strongly supports the importance for population health of deliberate social action, of a very explicit focus not only on medical care but on the non-medical determinants of health: education, nutrition, housing, employment and social cohesion. Pursuit of such policies ultimately requires political determination, although in countries with other political regimes, increasing wealth may have been part of the process of mobilizing support.

But what about all those Cuban doctors?

Szreter appears to take a relatively benign view of McKeown's "rhetorically powerful criti[que], from the inside, of the medical profession's mid-20th-century love affair with curative and scientific medicine" (Szreter 2002). It is the dismissal of public health, broadly or narrowly interpreted, that he challenges, not the medical scepticism. But there is no medical scepticism in Cuba. Along with efforts to address a broad range 
of non-medical determinants of health, Cuba has trained by far the world's largest supply of physicians per capita. Rather than seeing medical and non-medical determinants as competitive, Cuba has chosen, despite very limited resources, to go for both.

The difference appears to be that in Cuba, primary care physician (and nurse) teams have responsibility for the health of geographically defined populations, not merely of those patients who come in the door. These teams are then linked to community-and higher-level political organizations that both hold them accountable for the health of their populations and provide them with channels through which to influence the relevant non-medical determinants. To take on these roles, the medico familiar integrale (MFI) is trained in both the medical and the non-medical aspects of health.

Cuba has made operational the ideas sometimes described as "CommunityOriented Primary Care" (COPC) (Nutting 1984). The medical care system, rather than working in isolation from the non-medical determinants of health, becomes a key part of the process, the mechanisms of social intervention, through which those nonmedical determinants are addressed. And the success or otherwise of those interventions is then reflected in the epidemiological data collected as part of the regular functioning of the medical care system. More doctors, but with broader training and scope, more responsibility and institutionalized access to political authority.

Research on population health has made great progress in elucidating the determinants of population health, but has been much less successful in identifying the levers for translating this understanding into specific policies. The Cubans appear to have re-focused and heavily resourced medicine to address the non-medical determinants as well. The split between population health and clinical medicine that traces back to McKeown may have deprived population health of one of the most powerful mechanisms for translating understanding into practice.

On the other hand, it is highly unlikely that the ideological framework of clinical medicine in high-income societies could ever have permitted such a relationship, nor that the broader political context could sustain it. Has anyone heard of COPC lately? Anyway, our societies are achieving average levels of population health that match or exceed Cuba's, albeit at more than 10 times the cost for healthcare. And if we preserve a pronounced social gradient in health, well, it could be worse. I'm all right, Jack.

\section{ACKNOWLEDGEMENTS}

With thanks to Nino Pagliccia and Jerry Spiegel.

\section{NOTES}

1. The WHR tables include 192 countries, but I have excluded several for which the WHR advises "caution" in the use of the data. I have also arbitrarily excluded 
"micro-states" with populations less than one million from the world figures but not from the Americas, leaving 139 and 35 data points, respectively.

2. A version of Figure $1 b$, fitted in double logs with country points scaled to relative populations and colour-coded by continent, has been prepared by Hans Rosling of the Karolinska Institute. It shows the outlier status of Cuba even more dramatically, but was beyond our technical competence to reproduce. Available on request.

3. Actually, the highest ratio, 47.51, is in the Republic of San Marino - population 29,600 - but one has to suspect a tax haven. Coincidentally, according to the WHR, Canada and Cuba have virtually identical numbers of physicians $(66,583$ and 66,567), but Canada has only 2.14 physicians per capita.

\section{REFERENCES}

Evans, R.G. 2007.“Extravagant Americans, Healthier Canadians: The Bottom Line in North American Health Care." In D.M. Thomas and B.B. Torrey, eds., Canada and the United States: Differences That Count (pp. 135-64). Peterborough, ON: Broadview Press.

McKeown, T. 1979. The Role of Medicine: Dream, Mirage or Nemesis? (2nd ed.) Oxford: Basil Blackwell.

Nutting, P.A., ed. 1984. Community Oriented Primary Care: A Practical Assessment. Volumes 1-2. Washington, DC: Institute of Medicine.

Spiegel, J.M. and A. Yassi. 2004. "Lessons from the Margins of Globalization: Appreciating the Cuba Health Paradox." Journal of Public Health Policy 25(1): 96-121.

Szreter, S. 1988. “The Importance of Social Intervention in Britain's Mortality Decline c. 18501914: A Re-interpretation of the Role of Public Health." Society for the Social History of Medicine 1(1): 1-37.

Szreter, S. 2002."Rethinking McKeown: The Relationship between Public Health and Social Change." American Journal of Public Health 92(5): 722-25.

World Health Organization. 2006. World Health Report 2006 - Working Together for Health. Geneva: Author. 